\title{
KADAR HEMOGLOBIN (HB) IBU HAMIL DI PUSKESMAS BAHU MANADO
}

\author{
${ }^{1}$ Aprilia F. Lantu \\ ${ }^{2}$ Hermie M. M. Tendean \\ ${ }^{2}$ Eddy Suparman
}

\author{
${ }^{1}$ Kandidat Skripsi Fakultas Kedokteran Universitas Sam Ratulangi Manado \\ ${ }^{2}$ Bagian Obstetri dan Ginekologi Fakultas Kedokteran Universitas Sam Ratulangi - \\ RSUP Prof.Dr.R.D. Kandou Manado \\ Email: aprilialantu@hotmail.com
}

\begin{abstract}
Hemoglobin is a parameter used broadly to stipulate the anemia prevalence. Anemia is a medical condition where the amount of hemoglobin is abnormal. In pregnancy, if the level of hemoglobin $(\mathrm{Hb}<11 \mathrm{~g} / \mathrm{dL}$, then it is categorized as anemia. World health organization predicts that $35-75 \%$ of pregnant women in developing countries and $18 \%$ in developed countries are in anemia condition. According to WHO, the anemia prevalence globally on pregnant women is about $41,8 \%$. This research is intended to know the level of hemoglobin $(\mathrm{Hb})$ on pregnant women in Puskesmas Bahu Manado. This type of research is descriptive and prospective, observational study with cross sectional study design. Forty subjects participated in this research. After hemoglobin level checking, 13 people $(32,5 \%)$ with hemoglobin level $(\mathrm{Hb})<11 \mathrm{~g} / \mathrm{dL}$, and 27 people $(67,5 \%)$ with hemoglobin level $(\mathrm{Hb}) \geq 11$ $\mathrm{g} / \mathrm{dL}$. This study cocludes that: there are more pregnant women with normal level of $\mathrm{Hb}(\geq 11$ $\mathrm{g} / \mathrm{dL})$ in Puskesmas Bahu than the ones with lower level of $\mathrm{Hb}(<11 \mathrm{~g} / \mathrm{dL})$. The number of pregnant women in Puskesmas Bahu with normal $\mathrm{Hb}$ level is 27 people $(67,5 \%)$ of the total sample while there are 13 people with lower level of $\mathrm{Hb}(32,5 \%)$ of total sample.
\end{abstract}

Keywords: hemoglobin level, anemia, pregnant level

\begin{abstract}
Abstrak: Hemoglobin merupakan parameter yang digunakan secara luas untuk menetapkan prevalensi anemia. Anemia ialah suatu kondisi medis dimana jumlah sel darah merah atau hemoglobin $(\mathrm{Hb})$ kurang dari normal. Pada ibu hamil dikatakan anemia jika kadar hemoglobin $(\mathrm{Hb})<11 \mathrm{~g} / \mathrm{dL}$. World Health Organization (WHO) memperkirakan bahwa 35-75 \% ibu hamil di negara berkembang dan $18 \%$ ibu hamil di negara maju mengalami anemia. Menurut data WHO, secara global prevalensi anemia pada ibu hamil di seluruh dunia adalah sebesar 41,8\%. Penelitian ini bertujuan untuk mengetahui kadar hemoglobin $(\mathrm{Hb})$ ibu hamil di Puskesmas Bahu Manado. Jenis penelitian yang digunakan adalah penelitian observasional bersifat deskriptif prospektif dengan rancangan penelitian cross sectional (potong lintang). Empat puluh subjek berpartisipasi dalam penelitian ini. Setelah dilakukan pemeriksaan kadar hemoglobin $(\mathrm{Hb})$ didapatkan 13 orang $(32,5 \%)$ dengan kadar hemoglobin $(\mathrm{Hb})<11 \mathrm{~g} / \mathrm{dL}$, dan 27 orang $(67,5 \%)$ dengan kadar hemoglobin $(\mathrm{Hb}) \geq 11 \mathrm{~g} / \mathrm{dL}$. Berdasarkan hasil penelitian dapat disimpulkan bahwa: ibu hamil yang memiliki gambaran kadar $\mathrm{Hb}$ normal ( $\geq 11 \mathrm{~g} / \mathrm{dL}$ ) di Puskesmas Bahu ditemukan lebih banyak daripada ibu hamil yang memilliki kadar $\mathrm{Hb}$ rendah ( $<11 \mathrm{~g} / \mathrm{dL}$ ). Jumlah ibu hamil di Puskesmas Bahu yang memiliki kadar Hb normal adalah 27 orang $(67,5 \%)$ dari total sampel. Sedangkan ibu hamil di Puskesmas bahu yang memiliki kadar $\mathrm{Hb}$ rendah adalah 13 orang $(32,5 \%)$ dari total sampel.
\end{abstract}

Kata kunci: kadar hemoglobin, anemia, ibu hamil 
Pada kehamilan kebutuhan oksigen lebih tinggi sehingga memicu peningkatan produksi eritropoietin. Akibatnya, volume plasma bertambah dan sel darah merah (eritrosit) meningkat. Namun, peningkatan volume plasma terjadi dalam proporsi yang lebih besar jika dibandingkan dengan peningkatan eritrosit sehingga terjadi penurunan konsentrasi hemoglobin $(\mathrm{Hb})$ akibat hemodilusi. ${ }^{1}$

Hemoglobin merupakan parameter yang digunakan secara luas untuk menetapkan prevalensi anemia. ${ }^{2}$ Anemia ialah suatu kondisi medis dimana jumlah sel darah merah atau hemoglobin kurang dari normal. ${ }^{3}$ Pada ibu hamil dikatakan anemia jika kadar hemoglobin $(\mathrm{Hb})<11$ g/dL. ${ }^{1,4,5}$

Sebagian besar perempuan mengalami anemia selama kehamilan, baik di negara maju maupun negara berkembang. Badan Kesehatan Dunia atau World Health Organization (WHO) memperkirakan bahwa 35-75 \% ibu hamil di negara berkembang dan $18 \%$ ibu hamil di negara maju mengalami anemia. ${ }^{1}$ Menurut data WHO, secara global prevalensi anemia pada ibu hamil di seluruh dunia adalah sebesar 41,8\%. Prevalensi anemia pada ibu hamil diperkirakan di Asia sebesar 48,2 \%, Afrika 57,1 \%, Amerika 24,1 \%, dan Eropa $25,1 \%{ }^{6}$

Sedangkan menurut hasil Riset Kesehatan Dasar (Riskesdas) tahun 2013, prevalensi anemia pada ibu hamil di Indonesia sebesar $37,1 \%{ }^{7}$

Anemia sering terjadi akibat defisiensi zat besi karena pada ibu hamil terjadi peningkatan kebutuhan zat besi dua kali lipat akibat peningkatan volume darah tanpa ekspansi volume plasma, untuk memenuhi kebutuhan ibu (mencegah kehilangan darah pada saat melahirkan) dan pertumbuhan janin. ${ }^{8}$ Ironisnya, diestimasi dibawah $50 \%$ ibu tidak mempunyai cadangan zat besi yang cukup selama kehamilannya, sehingga risiko defisiensi zat besi atau anemia meningkat bersama dengan kehamilan. Hal ini telah dibuktikan di Thailand bahwa penyebab utama anemia pada ibu hamil adalah karena defisiensi besi $(43,1 \%){ }^{9}$ Disamping itu, studi di Malawi ditemukan dari 150 ibu hamil terdapat $32 \%$ mengalami defisiensi zat besi dan satu atau lebih mikronutrient. ${ }^{10}$ Demikian pula dengan studi di Tanzania memperlihatkan bahwa anemia ibu hamil berhubungan dengan defisiensi zat besi. ${ }^{11}$

Terdapat korelasi yang erat antara anemia pada saat kehamilan dengan kematian janin, abortus, cacat bawaan, berat bayi lahir rendah, cadangan zat besi yang berkurang pada anak atau anak lahir dalam keadaan anemia. Kondisi ini menyebabkan angka kematian perinatal masih tinggi, demikian pula dengan mortalitas dan morbiditas pada ibu. Selain itu, dapat mengakibatkan perdarahan pada saat persalinan yang merupakan penyebab utama kematian ibu hamil/bersalin di Indonesia. $^{12,13}$

Anemia disebabkan oleh berbagai faktor yang termasuk didalamnya faktor sosial ekonomi yaitu pendidikan, pekerjaan, dan pendapatan, dimana perbaikan ekonomi berperan terhadap pemenuhan gizi yang dalam hal ini ibu hamil dan hal ini didukung oleh hasil penelitian yang telah dilakukan oleh Pasaribu (2006) yang dari penelitian tersebut menjelaskan akan pengaruh sosial ekonomi terhadap kejadian anemia pada ibu hamil. ${ }^{14}$

Berdasarkan latar belakang masalah di atas, mendorong peneliti untuk melakukan penelitian dengan judul "Kadar Hemoglobin ( $\mathrm{Hb}$ ) Ibu Hamil Di Puskesmas Bahu Manado".

\section{METODE PENELITIAN}

Jenis penelitian yang digunakan adalah penelitian observasional bersifat deskriptif prospektif dengan rancangan penelitian cross sectional (potong lintang). Subjek penelitian ini adalah ibu hamil trimester I, II dan III di Puskesmas Bahu Manado.

\section{HASIL PENELITIAN DAN BAHASAN}

Pada penelitian di Puskesmas Bahu Manado Manado yang dilakukan dengan menggunakan jenis penelitian observasional bersifat deskriptif prospektif 
dengan menggunakan rancangan penelitian cross sectional (potong lintang), di dapatkan 40 wanita hamil yang sesuai dengan kriteria inklusi dan telah dilakukan pengambilan darah untuk pemeriksaan hemoglobin $(\mathrm{Hb})$. Pemeriksaan hemoglobin dilakukan di Laboratorium Klinik Prodia, jalan Sam Ratulangi nomor 72, Manado. Hasil penelitian dilakukan analisa mencakup karakteristik berdasarkan subjek penelitian, kadar hemoglobin $(\mathrm{Hb})$ berdasarkan karakteristik umur, usia kehamilan, paritas, pendidikan, pekerjaan. Hasil penelitian ini dirangkum dalam bentuk tabel seperti dibawah ini:

Tabel 1. Karakteristik Ibu Hamil

\begin{tabular}{lcc}
\hline \multicolumn{1}{c}{ Karakteristik } & $\mathbf{n}$ & $\mathbf{\%}$ \\
\hline Umur & & \\
$\leq 20$ & 6 & 15,0 \\
$21-34$ & 30 & 75,0 \\
$\geq 35$ & 4 & 10,0 \\
Total & 40 & 100,0 \\
\hline Usia Kehamilan & & \\
Trimester I & 6 & 15,0 \\
Trimester II & 21 & 52,5 \\
Trimester III & 13 & 32,5 \\
Total & 40 & 100,0 \\
\hline Paritas & & \\
Primigravida & 12 & 30,0 \\
Multigravida & 28 & 70,0 \\
Total & 40 & 100,0 \\
\hline Pendidikan & & \\
SMA & 26 & 65,0 \\
Sarjana & 14 & 35,0 \\
Total & 40 & 100,0 \\
\hline Pekerjaan & & \\
Bekerja & 19 & 47,5 \\
Tidak bekerja & 21 & 52,5 \\
Total & 40 & 100,0 \\
\hline
\end{tabular}

Pada Tabel 1 menunjukkan karakteristik ibu hamil. Berdasarkan umur, sampel terbanyak berada pada umur 21-34 tahun dengan jumlah 30 orang $(75,0 \%)$. Berdasarkan usia kehamilan, terbanyak pada trimester II dengan jumlah 21 orang $(52,5 \%)$. Berdasarkan paritas, terbanyak pada multigravida dengan jumlah 28 orang $(70,0 \%)$. Berdasarkan pendidikan, terbanyak pada tingkat SMA dengan jumlah 26 orang $(65,0 \%)$. Dan berdasarkan pekerjaan, terbanyak pada ibu hamil yang tidak bekerja yaitu, 21 orang $(52,5 \%)$.

Tabel 2.Distribusi Kadar Hemoglobin (Hb) Ibu Hamil

\begin{tabular}{ccc}
\hline $\begin{array}{c}\text { Kadar } \\
\text { Hemoglobin } \\
(\boldsymbol{g} / \boldsymbol{d} \boldsymbol{L})\end{array}$ & $\mathbf{N}$ & $\boldsymbol{\%}$ \\
\hline$<11 \mathrm{~g} / \mathrm{dL}$ & 13 & 32,5 \\
$\geq 11 \mathrm{~g} / \mathrm{dL}$ & 27 & 67,5 \\
Total & 40 & 100,0 \\
\hline
\end{tabular}

Pada Tabel 2 menunjukkan distribusi kadar Hemoglobin $(\mathrm{Hb})$ ibu hamil. Didapatkan jumlah terbanyak ibu hamil dengan kadar Hemoglobin $(H b) \geq 11$ g/dL yaitu, 27 orang $(67,5 \%)$.

Tabel 3. Karakteristik Ibu Hamil dengan Kadar Hemoglobin $(\mathrm{Hb})$

\begin{tabular}{|c|c|c|c|c|}
\hline \multirow{3}{*}{ Karakteristik } & \multicolumn{4}{|c|}{ Kadar Hemoglobin $(\mathrm{Hb})$} \\
\hline & \multicolumn{2}{|c|}{$<11 \mathrm{~g} / \mathrm{dL}$} & \multicolumn{2}{|c|}{$\geq 11 \mathrm{~g} / \mathrm{dL}$} \\
\hline & $\mathrm{n}$ & $\%$ & $\mathrm{n}$ & $\%$ \\
\hline \multicolumn{5}{|l|}{ Umur } \\
\hline$\leq 20$ & 3 & 7,5 & 3 & 7,5 \\
\hline $21-34$ & 9 & 22,5 & 21 & 52,5 \\
\hline$\geq 35$ & 1 & 2,5 & 3 & 7,5 \\
\hline Total & 13 & 100,0 & 27 & 100,0 \\
\hline \multicolumn{5}{|l|}{ Usia } \\
\hline \multicolumn{5}{|l|}{ Kehamilan } \\
\hline Trimester I & 2 & 5,0 & 4 & 10,0 \\
\hline Trimester II & 7 & 17,5 & 14 & 35,0 \\
\hline Trimester III & 4 & 10,0 & 9 & 22,5 \\
\hline Total & 13 & 100,0 & 27 & 100,0 \\
\hline \multicolumn{5}{|l|}{ Paritas } \\
\hline Primigravida & 6 & 15,0 & 6 & 15,0 \\
\hline Multigravida & 7 & 17,5 & 21 & 52,5 \\
\hline Total & 13 & 100,0 & 27 & 100,0 \\
\hline \multicolumn{5}{|l|}{ Pendidikan } \\
\hline SMA & 7 & 17,5 & 19 & 47,5 \\
\hline Sarjana & 6 & 15,0 & 8 & 20,0 \\
\hline Total & 13 & 100,0 & 27 & 100,0 \\
\hline \multicolumn{5}{|l|}{ Pekerjaan } \\
\hline Bekerja & 8 & 20,0 & 11 & 27,5 \\
\hline $\begin{array}{l}\text { Tidak } \\
\text { bekerja }\end{array}$ & 5 & 12,5 & 16 & 40,0 \\
\hline Total & 13 & 100,0 & 27 & 100,0 \\
\hline
\end{tabular}

Pada Tabel 3 berdasarkan umur, ibu hamil dengan kadar hemoglobin $(\mathrm{Hb}) \geq 11$ g/dL terbanyak pada usia 21-34 tahun 
dengan jumlah 21 orang $(52,5 \%)$. Berdasarkan usia kehamilan, terbanyak pada trimester II dengan jumlah 14 orang $(35,0 \%)$. Berdasarkan paritas, multigravida terbanyak dengan jumlah 21 orang (52,5\%). Berdasarkan pendidikan, terbanyak pada tingkat SMA dengan jumlah 19 orang $(47,5 \%)$. Dan berdasarkan pekerjaan, terbanyak pada ibu hamil yang tidak bekerja dengan jumlah 16 orang $(40,0 \%)$.

\section{SIMPULAN}

Berdasarkan hasil penelitian yang dilakukan terhadap 40 responden, maka dapat diambil kesimpulan sebagai berikut : Ibu hamil yang memiliki gambaran kadar Hb normal ( $\geq 11 \mathrm{~g} / \mathrm{dL})$ di Puskesmas Bahu ditemukan lebih banyak daripada ibu hamil yang memilliki kadar $\mathrm{Hb}$ rendah $(<11$ g/dL). Jumlah ibu hamil di Puskesmas Bahu yang memiliki kadar $\mathrm{Hb}$ normal adalah 27 orang $(67,5 \%)$ dari total sampel. Sedangkan ibu hamil di Puskesmas bahu yang memiliki kadar $\mathrm{Hb}$ rendah adalah 13 orang $(32,5 \%)$ dari total sampel.

\section{SARAN}

1. Dianjurkan melakukan kunjungan kehamilan secara rutin ke petugas kesehatan, mengkonsumsi makanan yang bergizi serta suplemen zat besi $(\mathrm{Fe})$ sesuai anjuran petugas kesehatan.

2. Diharapkan kepada petugas kesehatan baik perawat, bidan dan dokter dapat memberikan pendidikan kesehatan tentang pentingnya mengkonsumsi makanan bergizi bagi ibu hamil.

3. Diharapkan penelitian ini bisa dijadikan bahan referensi dan acuan untuk penelitian selanjutnya.

\section{DAFTAR PUSTAKA}

1. Prawirohardjo S. Ilmu Kebidanan. Edisi ke4. Jakarta: Bina Pustaka Sarwono Prawirohardjo; 2008 h.775-80.

2. Supariasa, I.D.N. Bachyar B. dan Ibnu F. Penilaian Status Gizi. Jakarta: EGC; 2002.

3. Proverawati A. Anemia dan Anemia Kehamilan. Cetakan I. Yogyakarta: Nuha Medika; 2011.
4. Saifuddin, A.B. Buku Acuan Nasional Pelayanan Kesehatan Maternal dan Neonatal. Jakarta: Yayasan Bina Pustaka Sarwono Prawirohardjo; 2002.

5. Marks PW. Pendekatan Anemia pada Anak dan Dewasa. Dlm: Hoffman R, Benz EJ, Shattil SS, eds. Hematologi. Edisi III. Philadelphia: Churchill Livingstone; 2010. h. 289-95.

6. WHO. Worldwide Prevalence of Anaemia. WHO global database on anemia geneva. World Health Organization. 2012.

7. Badan Penelitian Dan Pengembangan Kesehatan Kementerian Kesehatan RI. Riskesdas (Riset Kesehatan Dasar). 2013.

8. Cunningham dan Garry F. Obstetri Williams Edisi 21 Vol 2 [Hartono et al., trans]. Jakarta: Penerbit Buku Kedokteran EGC, 2014.

9. Sukrat B. and Sirichotiyakul S. The prevalence and causes of anemia during pregnancy in Maharaj Nakorn Chiang Mai Hospital. J. Med. Assoc. Thai 2006; 89(Suppl 4):S142-46.

10. Broek van den NR, Letsky EA. Etiology of anemia in pregnancy in south Malawi. Am. J. Clin. Nutr. 2000; 72(1):247S256S.

11.Hinderaker SG, Olsen BE, Lie RT, et al. Anemia in pregnancy in rural Tanzania: associations with micronutrients status and infections. Eur. J. Clin.Nutr. 2002; 56(3):192 199.

12. Ahmed F, Khan MR, Jackson AA. Concomitant Supplemental Vitamin A Enhances the Response to Weekly Supplemental Iron and Folic Acid in Anemic Teenagers In Urban Bangladesh. Am. J.Clin. Nutr. 2001; 74(1):108-115.

13.Departemen Kesehatan R.I. Program Penanggulangan Anemia Gizi pada Wanita Usia Subur (WUS); (Safe Motherhood Project: A Partnership and Family Approach). Direktorat Gizi Masyarakat. Jakarta: Direktorat Jenderal Bina Kesehatan Masyarakat Depkes, 2001.

14. Pasaribu D. R. Kejadian Anemia Pada Ibu Hamil Ditinjau Dari Sosial Ekonomi Dan Perolehan Tablet Zat Besi (Fe) Di Desa Maligas Tongah Kecamatan Tanah Jawa Kabupaten Simalungun Tahun 2006. 